\title{
Efficient and simple protocol employing borohydride systems to design a selective osthol-zirconium (OST-Zr) library from potential natural products
}

\author{
Radhakrishnan Viswanathan ${ }^{1,2}$, Imad A. Abu-Yousef ${ }^{3, *}$, Amin F. Majdalawieh ${ }^{3}$, Prince E. Das ${ }^{1}$ and \\ Srinivasan Narasimhan ${ }^{1, *}$ \\ ${ }^{1}$ Asthagiri Herbal Research Foundation, 162A, Perungudi Industrial Estate, Perungudi, Chennai, India 600096 \\ ${ }^{2}$ Department of Chemical Engineering, University of Pretoria, Pretoria 0002, South Africa \\ ${ }^{3}$ Department of Biology, Chemistry and Environmental Sciences, American University of Sharjah, P.O. Box \\ 26666, Sharjah, United Arab Emirates
}

\begin{abstract}
Drug likeness" of a molecule is the prime criterion for a molecule to exhibit the desired pharmaceutical activity. A pharmacophore, which describes molecular features that are necessary for molecular recognition of a ligand by a biological macromolecule, is well altered by the Structure Activity Relationship (SAR) guidelines through Hydrophobic Lipophilic Balance (HLB) demonstrated by the system. The tailoring is best accomplished by organic functional group interconversion on a potent natural product via a variety of synthetic methodologies available to date. Metal borohydrides $\left(\mathrm{MBH}_{4}\right)$ in particular are promising compounds as they can potentially serve varying HLB systems. The reagent acts on the substrate to cause reduction, hydroboration, or a combination of both outcomes for the purpose of rearrangement and fragmentation. Indeed, $\mathrm{Zr}\left(\mathrm{BH}_{4}\right)_{4}$ is expected to be more active and selective as a reducing agent compared to $\mathrm{NaBH}_{4}$. This study aims at evaluating zirconium borohydride $\left(\mathrm{Zr}\left(\mathrm{BH}_{4}\right)_{4}\right)$ in tetrahydrofuran (THF) as a reducing system to realize a more selective, meaningful and combinatorial osthol (OST) library from potential natural products and attempt to alternate preparation of the same in THF from known metal borohydrides, limiting reduction of the metal center versus metathesis.
\end{abstract}

Keywords: SAR (Structure Activity Relationship); HLB (Hydrophobic Lipophilic Balance); HTS (High Throughput Screening); metal borohydrides $\left(\mathrm{MBH}_{4}\right)$; metathesis

\section{Introduction}

Both electrophilic and nucleophilic boron reagents have been extensively utilized for modifying carbonyl-enes and -ynes to arrive at an appropriate product depending upon the reagent and conditions $^{1}$. Metal borohydrides of $\mathrm{Ca}$ and $\mathrm{Li}$ $\left(\mathrm{Ca}\left(\mathrm{BH}_{4}\right)_{2}\right.$ and $\left.\mathrm{LiBH}_{4}\right)$ are also known to hydroborate unsaturated systems in presence of esters with the exception being zinc borohydride ${ }^{2,3}$. The technique owes its superiority in avoiding borane dimethyl sulfide (BMS) and borane tetrahydrofuran (BTHF), which are relatively difficult systems to handle.

The anomalous nature of $\mathrm{Zn}\left(\mathrm{BH}_{4}\right)_{2}$ is well explained by its structure in contrast to other classes of borohydrides ${ }^{4}$.

In a natural product with plethora of functionalities capable of being treated by metal borohydrides and very reactive to promote hydroboration, reduction, or both in tandem, rearrangement followed by fragmentation is sought to generate a meaningful cocktail, which can be subjected to High Throughput Screening (HTS). Although this strategy is very simple and not robust, it is rather very efficient in scanning the permutation leading to a single entity. In our study, $\mathrm{Zr}\left(\mathrm{BH}_{4}\right)_{4}$ THF was chosen for analysis owing to high coordinating ability of $\mathrm{Zr}^{4+}$. Due to its oxidizing in nature, $\mathrm{Zr}^{4+}$ can transform simple borohydride to borane, which can be used for functional group interconversion, being structurally similar to $\mathrm{Zn}\left(\mathrm{BH}_{4}\right)_{2}$ (Figure 1). The high reactivity exhibited by $\mathrm{Zr}\left(\mathrm{BH}_{4}\right)_{4}$ towards unsaturated and carbonyl compounds can well be exploited to arrive at the desired outcome.

\footnotetext{
*Corresponding author: Imad A. Abu-Yousef, Srinivasan Narasimhan

Email adress : iabuyousef@aus.edu,narasimhan_s@yahoo.com

DOI : http://dx.doi.org/10.13171/mjc53/016041721/abuyousef
}

$\mid \begin{aligned} & \text { Received Mars } 14^{\text {th }}, 2016 \\ & \text { Accepted April 4 }{ }^{\text {th }}, 2016 \\ & \text { Published April } 17^{\text {th }}, 2016\end{aligned}$ 
Table 1. Structure of metal borohydrides ${ }^{5}$

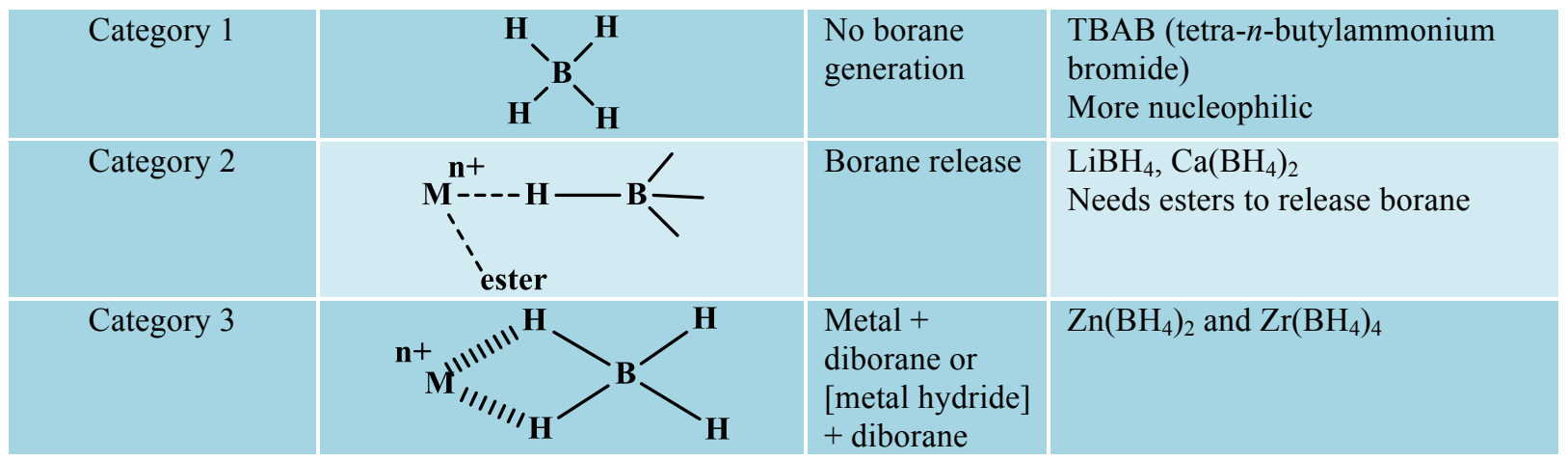

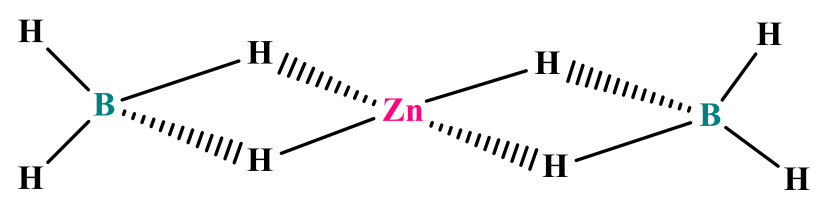

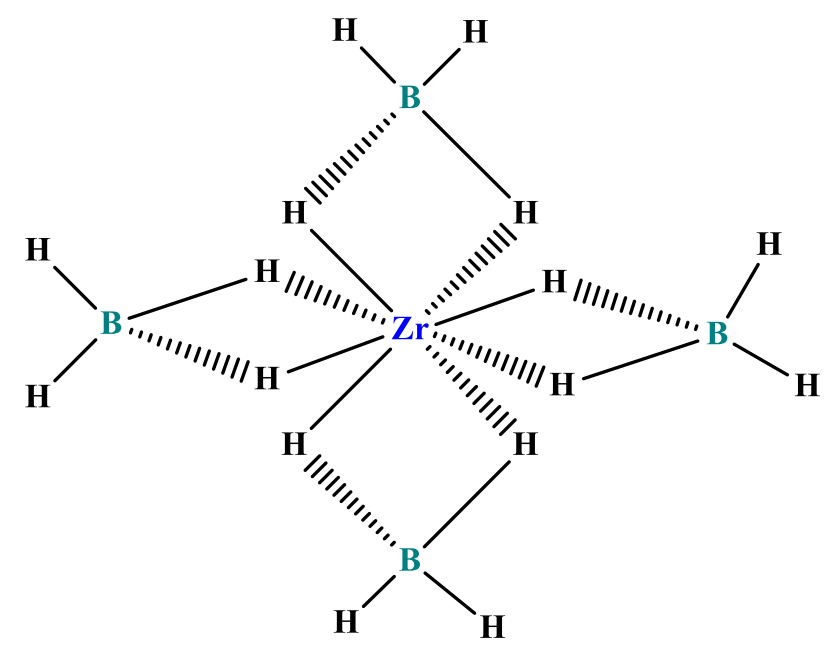

Figure 1. Structural similarity between $\mathrm{Zn}\left(\mathrm{BH}_{4}\right)_{2}$ and $\mathrm{Zr}\left(\mathrm{BH}_{4}\right)_{4}$.

An attempt has been made to prepare pure $\mathrm{Zr}\left(\mathrm{BH}_{4}\right)_{4}$-THF from other available metal borohydrides via metathesis and selection of a reducing system by monitoring their reaction profiles and species obtained ${ }^{6}$. In the literature, preparation of $\mathrm{Zr}\left(\mathrm{BH}_{4}\right)_{4}$ is claimed to be achieved by reacting $\mathrm{NaZrF}_{5}$ with excess $\mathrm{Al}\left(\mathrm{BH}_{4}\right)_{3}{ }^{7}$ or reacting $\mathrm{LiBH}_{4}$ with $\mathrm{ZrCl}_{4}$ either in solid state or in presence of a small quantity of ether ${ }^{8}$. Pure solid $\mathrm{Zr}\left(\mathrm{BH}_{4}\right)_{4}$ is highly pyrophoric and is known to decompose rapidly in solid state 9 . Hence, a solution of borohydride with prolonged shelf life in appropriate solvent, namely THF, becomes mandatory.

\section{Experimental Section}

$\mathrm{ZrCl}_{4}$ was purchased from Fluka Fine Chemicals. THF of analytical grade from Merck was distilled over benzophenone ketyl radical to ensure that it is moisture-free. The metal borohydrides of $\mathrm{Li}$, $\mathrm{Ca}$, and TBAB (tetra- $n$-butylammonium bromide) were prepared as per well documented methods ${ }^{10,11}$. HPLC analysis was performed on a Shimadzu LC10ATVP liquid chromatography fitted with a Luna $5 \mu \mathrm{m}$ column and UV-VIS detector. Acetonitrile:Water (60:40) (HPLC grade) was used as the mobile phase.

\section{Preparation of metal borohydride/ $\mathrm{ZrCl}_{4}$ reducing systems \\ To a flame-dried assembly of $100 \mathrm{~mL}$ two-neck round-bottom flask with a magnetic pellet fitted with a condenser leading to a gas bubbler attachment, a gentle stream of nitrogen was passed. $\mathrm{ZrCl}_{4} \quad(6$ mmol) was charged under nitrogen followed by 24 mmol of corresponding $\mathrm{MBH}_{4}$. Dry THF (25 mL)}


was introduced into the flask through double-pointed needle and the content was stirred at room temperature for 48 hours or refluxed for 7 hours. The clear supernatant solution was estimated for its $\mathrm{H}^{-}$ (hydride) content by quenching aliquots with $2 \mathrm{~N}$ $\mathrm{H}_{2} \mathrm{SO}_{4}$ and estimating the hydrogen evolved using a gas burette. The supernatant solution was used for the corresponding reaction.

\section{Kinetic study}

A mixture of $2.5 \mathrm{mmol}$ of $m$-nitro methylbenzoate and a certain volume of $\mathrm{MBH}_{4} / \mathrm{ZrCl}_{4} / \mathrm{THF}$ solution were taken in a pre-dried side-arm flask and the volume was adjusted to 10 $\mathrm{mL}$. The reaction mixture was stirred at ambient temperature and aliquots were withdrawn for the hydride estimation at suitable time intervals. The volume of $\mathrm{MBH}_{4} / \mathrm{ZrCl}_{4} / \mathrm{THF}$ solution was decided by estimating the hydride content of the reducing system and adding 5.2 volume of hydride (stoichiometry for ester reduction with allowances for loss in hydride due to moisture).

\section{library}

Design of combinatorial osthol-Zr (OST-Zr)

Oven-dried $50 \mathrm{~mL}$ round-bottom flask equipped with a side arm and a magnetic pellet was connected to a take-off adaptor leading to a mercury bubbler. The entire assembly was cooled under stream of nitrogen, and $2.0 \mathrm{mmol}$ of osthol was introduced instantaneously. Dry THF (10 mL) followed by 2.0 $\mathrm{M}$ of $\mathrm{NaBH}_{4} / \mathrm{ZrCl}_{4} / \mathrm{THF}$ reducing system $(9.5 \mathrm{~mL})$ was introduced into the flask via a syringe through a rubber septa fitted on the side arm. The content was stirred for 2 hours at room temperature and aliquots were drawn intermittently to monitor the disappearance of the starting material by Thin Liquid Chromatography (TLC). The reaction was quenched with ice-cold water while the reaction vessel was cooled with crushed ice. When hydrogen evolution ceased, $25 \%$ of ammonium hydroxide was added after complete precipitation of $\mathrm{Zr}(\mathrm{OH})_{4}$. The entire content was subsequently diluted with water and extracted with ethyl acetate/THF (EA/THF) mixture followed by EA. The organic layer was washed with brine and dried with anhydrous $\mathrm{Na}_{2} \mathrm{SO}_{4}$ and evaporated to yield the corresponding combinatorial library of OST-Zr in good yield.

\section{Results and Discussion}

Metathesis studies of $\mathrm{ZrCl}_{4}$ with other metal borohydrides in THF

Previously, Narasimhan and co-workers reacted $\mathrm{ZrCl}_{4}$ with $\mathrm{NaBH}_{4}(\mathrm{SBH})$ in THF to obtain $\mathrm{Zr}\left(\mathrm{BH}_{4}\right)_{4}$ and $\mathrm{BH}_{3}$ mixture ${ }^{6}$. The course of $\mathrm{Zr}\left(\mathrm{BH}_{4}\right)_{4}$ formation from $\mathrm{ZrCl}_{4}$ and $\mathrm{SBH}$ was followed by measuring the hydrogen evolved from the reaction and estimating the $\mathrm{H}^{-}$produced in the solution. The results are shown in Figure 2.

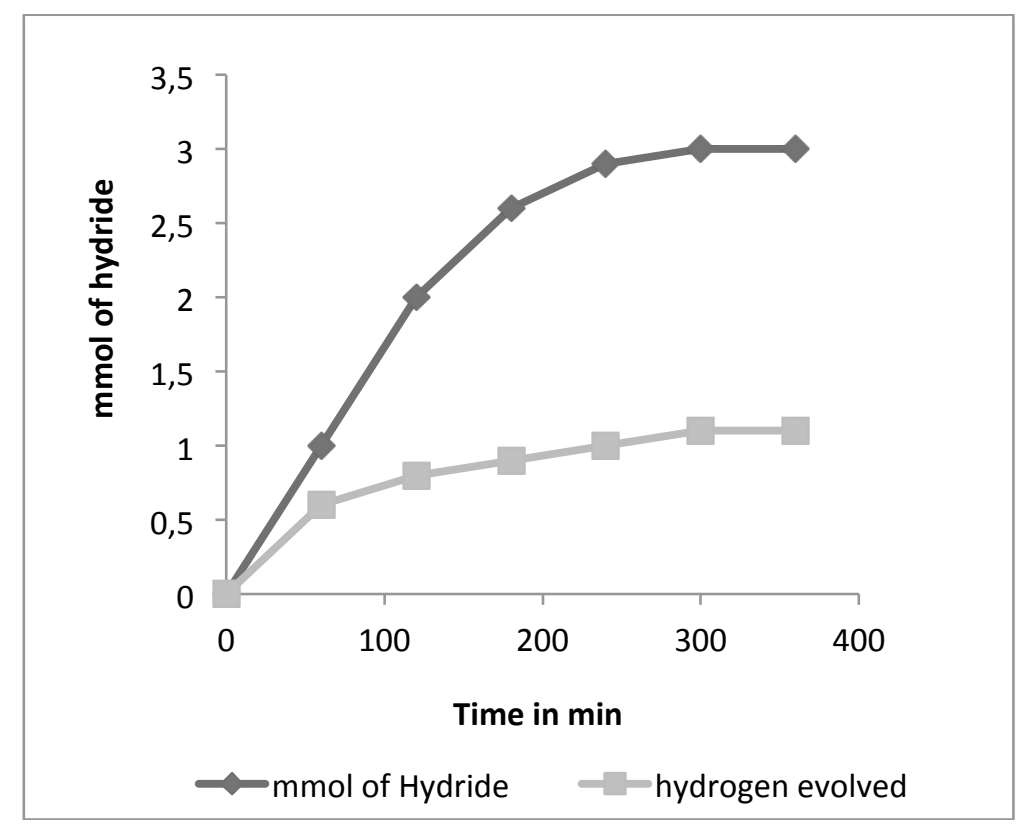

Figure 2. Kinetics of the formation of $\mathrm{Zr}\left(\mathrm{BH}_{4}\right)_{4}$.

Even though the solution contained $3.0 \mathrm{M}$ of hydride, no clear discrete signal for $\mathrm{BH}_{4}^{-}$was noticed until the $7^{\text {th }}$ hour, which confirms initial redox reaction and concomitant metathesis. Hence, the stoichiometry of the sequence was arrived as depicted in Scheme 1.

$$
\mathrm{ZrCl}_{4}+4 \mathrm{NaBH}_{4} \underset{25^{\circ} \mathrm{C}}{\stackrel{\mathrm{THF}}{\longrightarrow}} \mathrm{Zr}+4 \mathrm{BH}_{3}+2 \mathrm{H}_{2}+4 \mathrm{NaCl}
$$




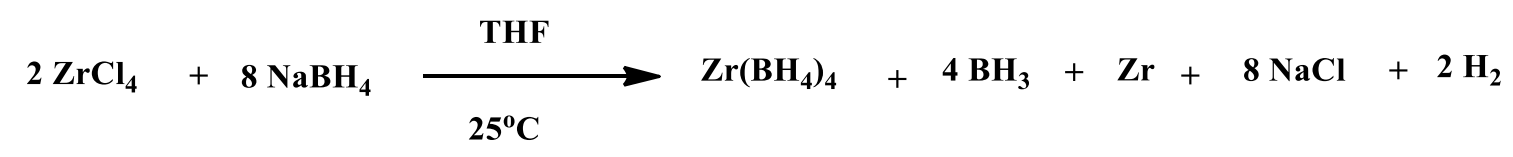

Scheme 1. Attempted synthesis of $\mathrm{Zr}\left(\mathrm{BH}_{4}\right)_{4}$.

Accordingly, 25\% of $\mathrm{H}_{2}$ liberation occurred and only $75 \%$ of $\mathrm{BH}_{4}^{-}$was formed. The corresponding observation has been constructed by ${ }^{11} \mathrm{~B}-\mathrm{NMR}$.

\section{Boron-11 NMR Study}

${ }^{11} \mathrm{~B}-\mathrm{NMR}$ experiments with clear supernatant THF solution of $\mathrm{Zr}\left(\mathrm{BH}_{4}\right)_{4}$ exhibited 3 resonance states (Table 2). $\mathrm{BF}_{3}-\mathrm{OEt}_{2}$ is used as a reference sample.

Table 2. Species envisaged during $\mathrm{Zr}\left(\mathrm{BH}_{4}\right)_{4}$ formation in THF

\begin{tabular}{|c|l|c|c|}
\hline S. No. & Species & $\boldsymbol{\delta}(\mathbf{p p m})$ & Multiplicity \\
\hline $\mathbf{1}$ & $\mathrm{BH}_{3}$ & -2 & Quartet \\
\hline $\mathbf{2}$ & $\mathrm{BH}_{4}^{-}$ & -7 & Quintet \\
\hline $\mathbf{3}$ & $\mathrm{B}_{2} \mathrm{H}_{7}^{-}$ & -26 & Septet \\
\hline
\end{tabular}

Hence, and as seen in Table 2, suppression of borane formation to predominantly drive metathesis is the objective. Metal borohydrides were employed to bring about metathesis exclusively avoid reduction of $\mathrm{Zr}^{4+}$ ion. $\mathrm{Ca}\left(\mathrm{BH}_{4}\right)_{2}, \mathrm{Zn}\left(\mathrm{BH}_{4}\right)_{2}, \mathrm{LiBH}_{4}$, and $\mathrm{Bu}_{4} \mathrm{NBH}_{4}$ were chosen as the representative borohydride reagents to drive metathesis with $\mathrm{ZrCl}_{4}$ in THF. As mentioned earlier, $\mathrm{LiBH}_{4}$ in ether was utilized for synthesis of $\mathrm{Zr}\left(\mathrm{BH}_{4}\right)_{4}{ }^{8}$, and we proposed to obtain the same results using a polar aprotic solvent like THF. It is well documented that the formation of $\mathrm{Bu}_{4} \mathrm{~N}\left[\mathrm{Zr}\left(\mathrm{BH}_{4}\right)_{5}\right]$ can be accomplished by reacting $\mathrm{Zr}\left(\mathrm{BH}_{4}\right)_{4}$ and $\mathrm{Bu}_{4} \mathrm{NBH}_{4}$ in benzene at ambient conditions ${ }^{12}$. Both $\mathrm{LiBH}_{4}$ and $\mathrm{Bu}_{4} \mathrm{NBH}_{4}$ were chosen to evaluate their behavior in THF and any combination that excels in its reactivity towards multifunctional molecule will therefore be best suited for our purpose.

With the exception of $\mathrm{Bu}_{4} \mathrm{NBH}_{4}$, which is prepared in an aqueous medium, all other metal borohydrides to drive metathesis were prepared, as shown in Scheme 2, by reacting SBH with metal halide salt in THF for a stipulated period of time as per the literature ${ }^{10}$.

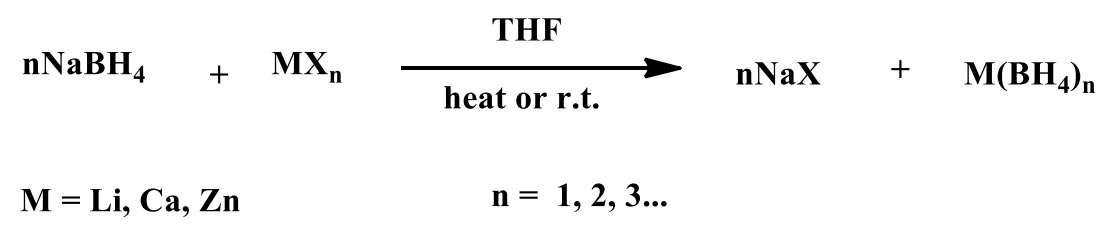

Scheme 2. Preparation of precursor metal borohydrides from the corresponding halide salt.

The prepared metal borohydrides were subsequently reacted with $\mathrm{ZrCl}_{4}$ in THF (Scheme 3) and the solutions were analyzed using ${ }^{11} \mathrm{~B}-\mathrm{NMR}$ (Table 3).

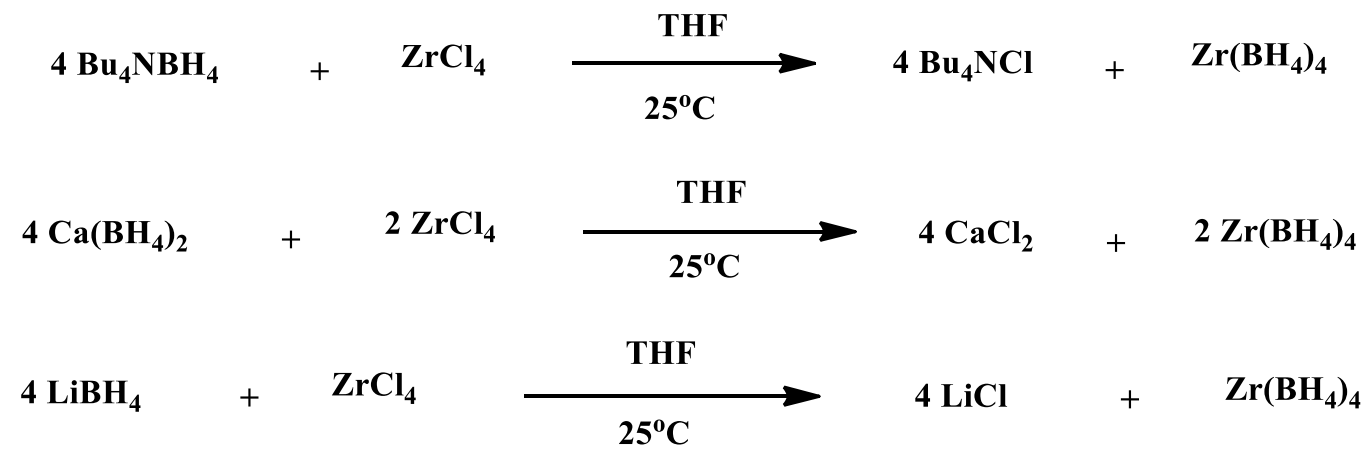

Scheme 3. Attempted synthesis of $\mathrm{Zr}\left(\mathrm{BH}_{4}\right)_{4}$ from representative metal borohydrides. 
Table 3. Boron species envisaged during metathesis reaction between $\mathrm{ZrCl}_{4}$ and representative metal borohydrides in THF

\begin{tabular}{|c|c|c|c|}
\hline S. No. & System & $\begin{array}{c}{ }^{11} \text { BNMR Signal * } \\
(\text { ppm) }\end{array}$ & Species \\
\hline 1 & $\mathrm{Zn}\left(\mathrm{BH}_{4}\right)_{2} / \mathrm{ZrCl}_{4}$ & $\begin{array}{l}-42 \\
-16 \\
-2\end{array}$ & $\begin{array}{c}\mathrm{Zn}\left(\mathrm{BH}_{4}\right)_{2} \text { quintet } \\
\text { Borane quartet }\end{array}$ \\
\hline 2 & $\mathrm{Ca}\left(\mathrm{BH}_{4}\right)_{2} / \mathrm{ZrCl}_{4}$ & $\begin{array}{c}-36 \\
-28 \\
-15 \\
-8 \\
-0\end{array}$ & $\begin{array}{l}\mathrm{Ca}\left(\mathrm{BH}_{4}\right)_{2} \text { quintet } \\
\qquad \mathrm{B}_{2} \mathrm{H}_{7} \text { - septet } \\
\text { Trace of } \mathrm{Zr}\left(\mathrm{BH}_{4}\right)_{4} \\
\text { Borane quartet }\end{array}$ \\
\hline 3 & $\mathrm{LiBH}_{4} / \mathrm{ZrCl}_{4}$ & $\begin{array}{c}-42 \\
-25 \\
-15 \\
-12 \\
-1\end{array}$ & $\begin{array}{l}\mathrm{LiBH}_{4} \text { quintet } \\
\mathrm{B}_{2} \mathrm{H}_{7} \text { - septet } \\
\text { Borane quartet }\end{array}$ \\
\hline 4 & $\mathrm{TBAB} / \mathrm{ZrCl}_{4}$ & $\begin{array}{c}-37 \\
-24 \\
-15 \\
-8\end{array}$ & $\begin{array}{c}\text { TBAB quintet } \\
\mathrm{B}_{2} \mathrm{H}_{7^{-}} \text {septet } \\
\text { Trace of } \mathrm{Zr}\left(\mathrm{BH}_{4}\right)_{4}\end{array}$ \\
\hline
\end{tabular}

$* \mathrm{BF}_{3} . \mathrm{OEt}_{2}$ was used as a reference.

In all cases studied, except $\mathrm{NaBH}_{4}$, the precursor metal borohydride remained in high concentration with trace quantities of $\mathrm{Zr}\left(\mathrm{BH}_{4}\right)_{4}$, and signals at -25 ppm and -1 ppm corresponding to $\mathrm{B}_{2} \mathrm{H}_{7}$ and $\mathrm{BH}_{3}$ clearly suggest reduction of $\mathrm{Zr}^{4+}$. Signals in the range of -10 to $-15 \mathrm{ppm}$ can presumably arise from the mono anionic species.

Evaluation of the reagent systems towards reduction

The reactivity of metal borohydride solutions from metathesis reaction were assessed by reacting them with an aromatic ester, namely $m$ nitromethylbenzoate (Scheme 4). $m$-Nitro methyl benzoate was chosen as the representative substrate to evolve kinetics of reduction with various borohydride $/ \mathrm{ZrCl}_{4}$ systems in THF. Aliquots were obtained at various time intervals and quenched with $2 \mathrm{M}\left(\mathrm{NH}_{4}\right)_{2} \mathrm{SO}_{4}$. The evolved hydrogen gas was measured using gas burette (Table 4). Upon completion of the reaction, the nitro group remained untouched as confirmed by IR measurements.<smiles>COC(=O)c1cccc([N+](=O)[O-])c1</smiles>

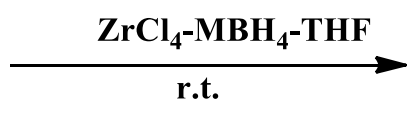<smiles>O=[N+]([O-])c1cccc(CO)c1</smiles>

$$
\mathrm{M}=\mathrm{Ca}, \mathrm{Zn}, \mathrm{Li}, \mathrm{Na}, \mathrm{Bu}_{4} \mathrm{~N}
$$

Scheme 4. Reactivity of metal borohydrides obtained from metathesis reactions.

Table 4. Kinetics of reduction of $m$-nitromethylbenzoate with a reducingcMBH$/ \mathrm{ZrCl}_{4} / \mathrm{THF}$ system

\begin{tabular}{|c|c|c|c|c|c|c|c|c|c|c|c|c|c|c|}
\hline Time (min) & $\mathbf{0}$ & 10 & 15 & 30 & 45 & 60 & 75 & 90 & 115 & 130 & 145 & 160 & 175 & 190 \\
\hline System & \multicolumn{14}{|c|}{$\%$ Reaction } \\
\hline $\mathrm{NaBH}_{4} / \mathrm{ZrCl}_{4} / \mathrm{THF}$ & 0 & 40 & & 68 & & 80 & & 92 & & & & & & \\
\hline $\mathrm{LiBH}_{4} / \mathrm{ZrCl}_{4} / \mathrm{THF}$ & 0 & & 46.6 & & 52 & 68 & 68 & & 76 & & & & 76 & 81.3 \\
\hline $\mathrm{Zn}\left(\mathrm{BH}_{4}\right)_{2} / \mathrm{ZrCl}_{4} / \mathrm{THF}$ & 0 & 0 & 0 & 20 & & & 37 & 46 & & 46.6 & 46.6 & 46.6 & & 82.2 \\
\hline $\mathrm{TBAB} / \mathrm{ZrCl}_{4} / \mathrm{THF}$ & 0 & & 84 & 84 & 84 & & 84 & & & & & & & \\
\hline $\mathrm{Ca}\left(\mathrm{BH}_{4}\right)_{2} / \mathrm{ZrCl}_{4} / \mathrm{THF}$ & 0 & & 40 & & 40 & & 60 & 60 & 60 & 60 & 60 & 60 & 60 & \\
\hline
\end{tabular}


In all the reactions, the nitro group was unaffected. The order of reactivity of various reducing systems in THF is as follows:

$$
\mathrm{TBAB} / \mathrm{ZrCl}_{4}>\mathrm{LiBH}_{4} / \mathrm{ZrCl}_{4}>\mathrm{Ca}\left(\mathrm{BH}_{4}\right)_{2} / \mathrm{ZrCl}_{4}>\mathrm{Zn}\left(\mathrm{BH}_{4}\right)_{2} / \mathrm{ZrCl}_{4}
$$

It is well documented in literature that $\mathrm{Zr}\left(\mathrm{BH}_{4}\right)_{4}$ behaves as Lewis acid in a reaction with $\mathrm{R}_{4} \mathrm{NBH}_{4}$ and $\mathrm{LiBH}_{4}$, yielding $\left[\mathrm{NBu}_{4}\right]\left[\mathrm{Zr}\left(\mathrm{BH}_{4}\right)_{5}\right]$ and $\operatorname{LiZr}\left(\mathrm{BH}_{4}\right)_{5}{ }^{12}$. This explains the order of reactivity towards esters. Even though a reducing system comprised of TBAB marginally surpasses $\mathrm{SBH}$, $\mathrm{NaBH}_{4} / \mathrm{ZrCl}_{4} / \mathrm{THF}$ system was chosen for designing the combinatorial library due to cost effectiveness and better ${ }^{11} \mathrm{~B}-\mathrm{NMR}$ profile. It is noteworthy that a trivalent species can aid in enhancing reduction capabilities of a $\mathrm{BH}_{4}$ and vice versa ${ }^{13}$. A powerful "combinatorial reagent" containing $\mathrm{BH}_{3} / \mathrm{BH}_{4}$ - is well realized through $\mathrm{NaBH}_{4} / \mathrm{ZrCl}_{4} / \mathrm{THF}$ system.

\section{Design of combinatorial OST-Zr library}

The reagent was tested upon osthol, a coumarin class of molecules with an additional isoprenyl and methoxy moiety ${ }^{14}$. Relevance of biological activity of osthol is well documented in the literature ${ }^{15}$, and hence, it is worthy to study its analogs and arrive at a rationale with SAR formalism. To this end, osthol was treated with excess hydride to ensure completion of reaction as shown in Scheme 5. The reaction in THF with $\mathrm{NaBH}_{4} / \mathrm{ZrCl}_{4} / \mathrm{THF}$ reducing system was monitored periodically for 2 hours until the substrate vanished.

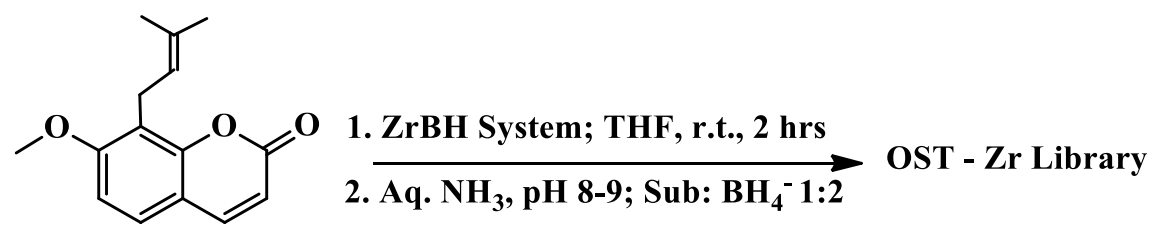

Scheme 5. Library of osthol analogs employing $\mathrm{NaBH}_{4} / \mathrm{ZrCl}_{4} / \mathrm{THF}$ reducing system.

The mixture was worked up using ammonium hydroxide to yield the mixture. As shown in Figure 3 and Table 5, HPLC analysis on a reverse phase
(RP) phenomenex column with UV detector set at $205 \mathrm{~nm}$ exhibited 12 peaks with percentage peak areas.

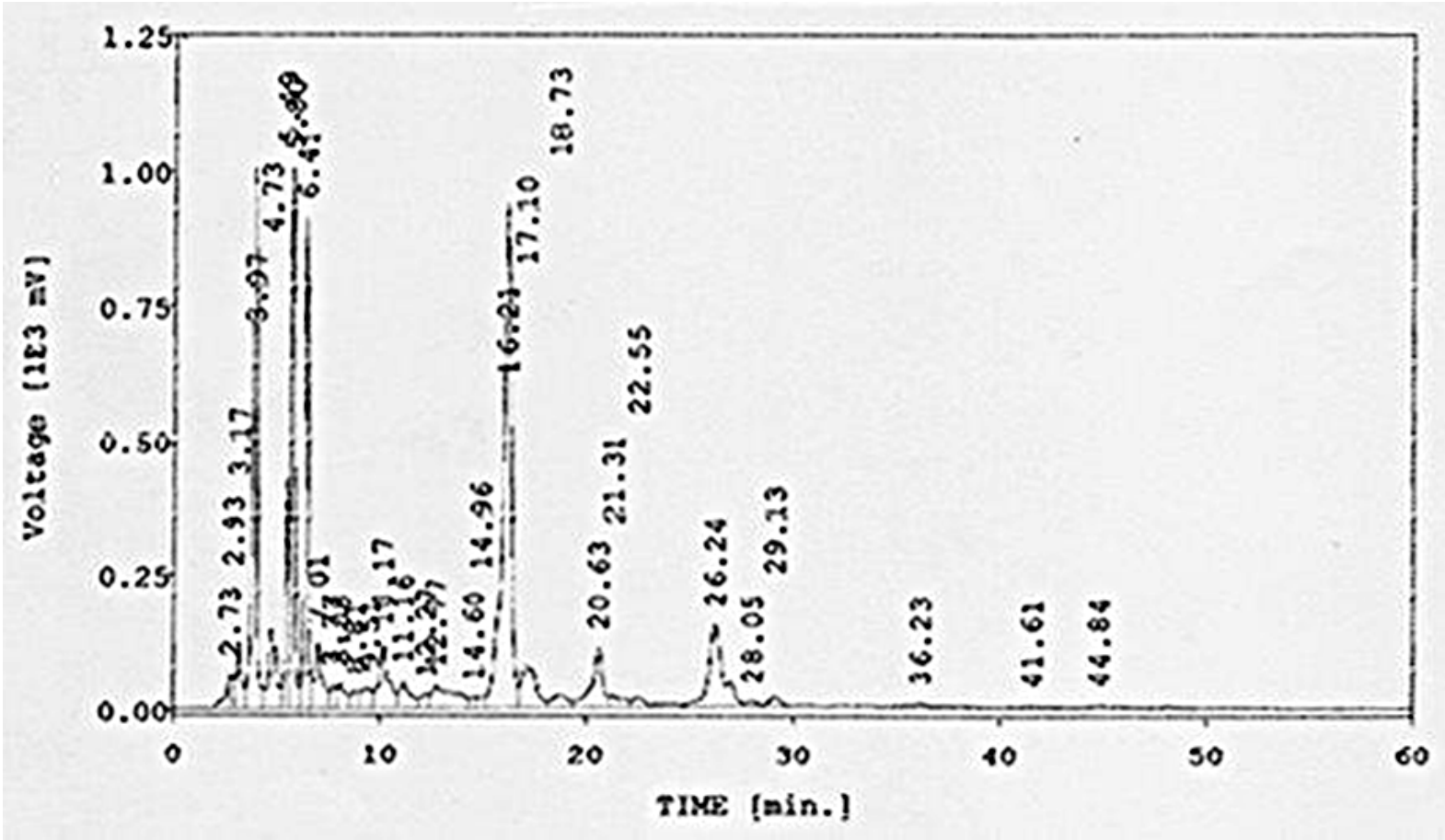

Figure 3. HPLC chromatogram of OST-Zr library. 
Table 5. HPLC analysis on a RP phenomenex column with UV detector set at $205 \mathrm{~nm}$

\begin{tabular}{|ccllccc|}
\hline Peak No. & $\begin{array}{c}\text { Retention } \\
\text { Time }\end{array}$ & $\begin{array}{c}\text { Area } \\
{[\mathrm{mV} \text {.s. }}\end{array}$ & $\begin{array}{c}\text { Height } \\
{[\mathrm{mV}]}\end{array}$ & $\begin{array}{c}\text { W05 } \\
{[\mathrm{min} .]}\end{array}$ & $\begin{array}{c}\text { Area } \\
{[\%]}\end{array}$ & $\begin{array}{c}\text { Height } \\
{[\%]}\end{array}$ \\
\hline $\mathbf{1}$ & 2.733 & 994.4124 & 62.6049 & 0.1600 & 0.8499 & 1.1088 \\
\hline $\mathbf{2}$ & 2.927 & 776.8155 & 67.4334 & 0.2200 & 0.6639 & 1.1943 \\
\hline $\mathbf{3}$ & 3.173 & 1840.5976 & 117.9011 & 0.2000 & 1.5731 & 2.0881 \\
\hline $\mathbf{4}$ & 3.973 & 15710.9129 & 1002.8093 & 0.2267 & 13.4273 & 17.7605 \\
\hline $\mathbf{5}$ & 4.733 & 3790.1901 & 147.6512 & 0.3600 & 3.2393 & 2.6150 \\
\hline $\mathbf{6}$ & 5.493 & 4427.7678 & 427.8726 & 0.1867 & 3.7842 & 7.5779 \\
\hline $\mathbf{7}$ & 5.800 & 14659.1926 & 1002.2826 & 0.2200 & 12.5285 & 17.7512 \\
\hline $\mathbf{8}$ & 6.412 & 10103.0176 & 910.4496 & 0.1667 & 8.6345 & 16.1247 \\
\hline $\mathbf{9}$ & 7.007 & 3150.1744 & 120.6316 & 0.2867 & 2.6923 & 2.1365 \\
\hline $\mathbf{1 0}$ & 7.767 & 776.7693 & 42.3989 & 0.3600 & 0.6656 & 0.7509 \\
\hline $\mathbf{1 1}$ & 8.080 & 1223.7135 & 44.4892 & 0.6333 & 1.0458 & 0.7879 \\
\hline $\mathbf{1 2}$ & 8.807 & 707.1614 & 31.8901 & 0.4133 & 0.6044 & 0.5648 \\
\hline $\mathbf{1 3}$ & 9.507 & 1390.5606 & 35.5104 & 0.7200 & 1.1884 & 0.6289 \\
\hline $\mathbf{1 4}$ & 10.173 & 3651.4934 & 116.0568 & 0.3000 & 3.1207 & 2.0555 \\
\hline $\mathbf{1 5}$ & 11.160 & 1810.2434 & 47.4526 & 0.6800 & 1.5471 & 0.8404 \\
\hline $\mathbf{1 6}$ & 12.273 & 676.3804 & 25.9815 & 0.5200 & 0.5781 & 0.4602 \\
\hline $\mathbf{1 7}$ & 12.767 & 3131.9740 & 39.0271 & 1.7867 & 2.6767 & 0.6912 \\
\hline $\mathbf{1 8}$ & 14.600 & 390.2025 & 18.4406 & 0.3733 & 0.3335 & 0.3266 \\
\hline $\mathbf{1 9}$ & 14.960 & 458.3020 & 20.1146 & 0.4000 & 0.3917 & 0.3562 \\
\hline $\mathbf{2 0}$ & 16.207 & 26173.3859 & 933.7167 & 0.3600 & 22.3691 & 16.5368 \\
\hline $\mathbf{2 1}$ & 17.100 & 3941.8494 & 78.4846 & 0.8467 & 3.3689 & 1.3900 \\
\hline $\mathbf{2 2}$ & 18.727 & 1121.5591 & 20.5466 & 1.0000 & 0.9585 & 0.3639 \\
\hline $\mathbf{2 3}$ & 20.633 & 4037.6683 & 108.2753 & 0.4467 & 3.4508 & 1.9176 \\
\hline $\mathbf{2 4}$ & 21.307 & 980.6145 & 20.6780 & 1.0733 & 0.8381 & 0.3662 \\
\hline $\mathbf{2 5}$ & 22.553 & 1067.1210 & 15.4004 & 0.7467 & 0.9120 & 0.2728 \\
\hline $\mathbf{2 6}$ & 26.240 & 7263.8617 & 150.4594 & 0.5733 & 6.2081 & 2.6647 \\
\hline $\mathbf{2 7}$ & 28.047 & 324.8539 & 8.5089 & 0.7267 & 0.2776 & 0.1507 \\
\hline $\mathbf{2 8}$ & 29.133 & 590.0719 & 16.9672 & 0.5467 & 0.5043 & 0.3009 \\
\hline $\mathbf{2 9}$ & 36.233 & 738.9559 & 5.5480 & 1.5600 & 0.6315 & 0.0983 \\
\hline $\mathbf{3 0}$ & 41.613 & 334.5785 & 2.7227 & 1.6200 & 0.2859 & 0.0482 \\
\hline $\mathbf{3 1}$ & 44.840 & 760.7024 & 3.9630 & 1.9667 & 0.6502 & 0.0703 \\
\hline
\end{tabular}

The vast majority of polar peaks are spanned in the time range of 0 to $20 \mathrm{~min}$. Our aim is to analytically understand the maximized product generation that could possibly result in hit to lead, which is one of the early stages of drug discovery. A powerful hyphenated chromatographic method (LCMS) coupled with robust HTS is the ultimatum in the study.

A simple demonstration of attempted library design with $\mathrm{NaBH}_{4} / \mathrm{ZrCl}_{4} / \mathrm{THF}$ reducing system on osthol resulted in 12 peaks with percentage peak area $\geq 2$. A wide variety of metal borohydride reducing systems with different reactivity potentials to influence functional group interconversion are best suited for conventional parallel synthetic strategies towards combinatorial libraries. Chances of reaction selectivity is welcome but the choice of work up and reaction parameter like solvent stoichiometry further widens the multiplicative factor of product formation. Moreover, when the libraries are profiled with hyphenated chromatographic techniques coupled with appropriate HTS, this will aid in achieving the hit molecule.

\section{Conclusion}

A simple demonstration of attempted osthol library design with $\mathrm{NaBH}_{4} / \mathrm{ZrCl}_{4} / \mathrm{THF}$ reducing system on osthol resulted in 12 peaks which are taken for HTS. The method is quiet simple with manageable chemical entities which are closely related structurally. $\mathrm{Zr}\left(\mathrm{BH}_{4}\right)_{4}$ is expected to be more active and selective as a reducing agent compared to $\mathrm{NaBH}_{4}$. In principle, it can be expected to have a good SAR and mimic a fraction of potent natural product extract. A wide variety of metal borohydride reducing systems with different reactivity potentials to influence functional group interconversion are best suited for conventional parallel synthetic strategies towards combinatorial libraries. Chances of reaction selectivity depend on the nature and number of boron species formed which can aid in multiplicative product formation. Additionally the choice of reaction work-up allows the flexibility to achieve functionally different molecule which broadens the scope to realize a hit molecule. Our study demonstrates that $\mathrm{Zr}\left(\mathrm{BH}_{4}\right)_{4}$-THF is an 
effective reducing system that allows the design of a more selective, meaningful and combinatorial osthol (OST) library from potential natural products. Our study also shows that comparable results are achieved by preparing similar systems using other known metal borohydrides, limiting reduction of the metal center versus metathesis.

\section{References}

1- A. Pelter, K. Smith and H. C. Brown, Borane Reagents; Academic Press: New York, 1988.

2- S. Narasimhan, K. G. Prasad, S. Madhavan, Synthetic. Commun., 1995, 25(11), 1689-1697.

3- S. Narasimhan, K. G. Prasad, S. Madhavan, Synthetic. Commun., 1996, 26(4), 703-706.

4- S. Narasimhan, R. Balakumar, Alsrichimica Acta., 1998, 31(1), 19-26.

5- T. J. Marks, J. R. Kolb, Chem. Soc. Rev., 1977, 77, 263-293.
6- S. Narasimhan, R. Balakumar, Synthetic. Commun., 2000, 30(23), 4387- 4395.

7- H. R. Hoekstra, J. J. Katz, J. Am. Chem. Soc., 1949, 71, 2488-2492.

8- B. D. James, B. E. Smith, Synth. React. Inorg. Metal-Org. Chem., 1974, 4, 461- 465.

9- E. Jeon, Y. W. E. Cho, J. Alloys Compd., 2006, 422(1-2), 273-275.

10- H. C. Brown, Y. M. Choi, S. Narasimhan, Inorg. Chem., 1981, 20, 4454- 4456.

11- S. Narasimhan, S. Swarnalakshmi, R. Balakumar, S. Velmathi, Synthetic. Commun., 1999, 29(4), 685-689.

12- M. Ehemann, H. Noth, Z. Anrog. Allg. Chem., 1971, 386, 87-101.

13- H. C. Brown, S. C. Kim, S. Krishnamurthy, J. Org. Chem., 1980, 45, 1-12.

14- S. K. Kapwoor, Phytochemistry, 1968, 7 , 147-149.

15- W. C. Evans, Trease and Evans Pharmacognasy, $14^{\text {th }}$ Edition; W. B. Saunders Co.: London, 1996. 